University of the Pacific

Scholarly Commons

Fall 9-1-2008

\title{
Expanding circle of inhibition: small-molecule inhibitors of Bcl-2 asanticancer cell and antiangiogenic agents
}

\author{
Benjamin David Zeitlin \\ University of the Pacific, bzeitlin@pacific.edu \\ Isaac J. Zeitlin \\ University of Strathclyde \\ Jacques E. Nör \\ University of Michigan School of Dentistry, jenor@umich.edu
}

Follow this and additional works at: https://scholarlycommons.pacific.edu/dugoni-facarticles

Part of the Dentistry Commons

\section{Recommended Citation}

Zeitlin, B. D., Zeitlin, I. J., \& Nör, J. E. (2008). Expanding circle of inhibition: small-molecule inhibitors of Bcl-2 asanticancer cell and antiangiogenic agents. Journal of Clinical Oncology, 26(25), 4180-4188. DOI: 10.1200/JC0.2007.15.7693

https://scholarlycommons.pacific.edu/dugoni-facarticles/390

This Article is brought to you for free and open access by the All Faculty Scholarship at Scholarly Commons. It has been accepted for inclusion in All Dugoni School of Dentistry Faculty Articles by an authorized administrator of Scholarly Commons. For more information, please contact mgibney@pacific.edu. 
From the Department of Restorative Sciences, University of Michigan School of Dentistry, and University of Michigan Comprehensive Cancer Center, Ann Arbor, Ml; and University of Strathclyde, Glasgow, Scotland

United Kingdom

Submitted December 12, 2007 accepted April 29, 2008.

Supported by Grants No. R01-DE14601 R01-DE15948, and R01-DE16586 from the National Institutes of Health/ National Institute of Dental and Craniofacial Research (J.E.N.) and a developmental project from the University of Michigan Head and Neck Specialized Program of Research Excellence (J.E.N).

Terms in blue are defined in the glossary, found at the end of this article and online at www.jco.org.

Authors' disclosures of potential conflicts of interest and author contributions are found at the end of this article.

Corresponding author: Jacques E. Nör, $\mathrm{PhD}$, Angiogenesis Research Laboratory, University of Michigan, $1011 \mathrm{~N}$ University Rm 2309, Ann Arbor, MI 48109-1078; e-mail: jenor@umich.edu.

(C) 2008 by American Society of Clinical Oncology

0732-183X/08/2625-4180/\$20.00

DOI: $10.1200 / J C O .2007 .15 .7693$

\section{Expanding Circle of Inhibition: Small-Molecule Inhibitors of Bcl-2 as Anticancer Cell and Antiangiogenic Agents}

Benjamin D. Zeitlin, Isaac J. Zeitlin, and Jacques E. Nör

$$
\begin{array}{llllllll}
\text { A } & \text { B } & \text { S } & \text { T } & \text { R } & \text { A } & \text { C } & \text { T }
\end{array}
$$

The specific targeting of diseases, particularly cancer, is a primary aim in drug development, as specificity reduces unwelcome effects on healthy tissue and increases drug efficacy at the target site. Drug specificity can be increased by improving the delivery system or by selecting drugs with affinity for a molecular ligand specific to the disease state. The role of the prosurvival Bcl-2 protein in maintaining the normal balance between apoptosis and cellular survival has been recognized for more than a decade. Bcl-2 is vital during development, much less so in adults. It has also been noted that some cancers evade apoptosis and obtain a survival advantage through aberrant expression of $\mathrm{Bcl}-2$. The new and remarkably diverse class of drugs, small-molecule inhibitors of Bcl-2 (molecular weight approximately 400 to 800 Daltons), is examined herein. We present the activities of these compounds along with clinical observations, where available. The effects of Bcl-2 inhibition on attenuation of tumor cell growth are discussed, as are studies revealing the potential for $\mathrm{Bcl}-2$ inhibitors as antiangiogenic agents. Despite an enormous body of work published for the Bcl-2 family of proteins, we are still learning exactly how this group of molecules interacts and indeed what they do. The small-molecule inhibitors of Bcl-2, in addition to their therapeutic potential, are proving to be an important investigative tool for understanding the function of $\mathrm{Bcl}-2$.

\section{J Clin Oncol 26:4180-4188. (C) 2008 by American Society of Clinical Oncology}

\section{INTRODUCTION}

Evolution has adapted us more poorly to fight cancer compared with almost any other disease, and until recent years, approaches to treatment of cancer had changed little. Physical removal of the tumor by surgery remains an important first-line treatment but lacks effectiveness in the face of highly aggressive or invasive cancers, cancers that are difficult to detect, or those that have reached a metastatic stage. Radiotherapy and chemotherapy are the conventional second-line treatments; however, both are nonspecific to the tumor tissue. They are generally toxic to healthy tissue and, notably for DNA-directed drugs such as cisplatin (cisdiamminedichloroplatinum), may ultimately be carcinogenic in their own right. ${ }^{1,2}$

This review deals with a novel class of targeted drugs developed by several independent groups over the last few years: small-molecule inhibitors of the antiapoptotic protein Bcl-2 (B-cell lymphoma/leukemia-2). The antitumor and antiangiogenic potential of these compounds will be discussed. In the literature, the term Bcl-2 inhibitor encompasses various drugs that bind the antiapoptotic Bcl-2 family members with more or less effi- cacy. None of the compounds here discussed are specific to only one member of the Bcl-2 family.

\section{BCL-2-RELATED PROTEIN FAMILY}

$\mathrm{Bcl}-2$ is a $26-\mathrm{kDa}$ protein localized to the mitochondria and endoplasmic reticulum that acts as a key inhibitor of apoptosis. Expression of Bcl-2 is essential for growth of certain tumor cell lines in vitro and has been found upregulated in a variety of tumor types in vivo. ${ }^{3-5}$ The interactions of other Bcl-2 family members and their role in modulating Bcl-2 functions have been reviewed, ${ }^{6,7}$ and a detailed discussion of such is beyond the scope of this review. A brief description here may aid the appreciation of drug actions. Bcl-2 and other members of the family are primary regulators of apoptosis (Fig 1). They maintain a balance within the cell that is biased toward survival. Bcl-2 structure consists of five domains, Bcl-2 homology (BH) domains 1 to 4 plus a transmembrane domain (Fig 2). The other Bcl-2 family members bear four or fewer of these domains and display varying degrees of homology (Fig 2). The BH1-3 domains can form a labile hydrophobic groove, on tertiary folding, that allows binding of other molecules via their own $\mathrm{BH} 3$ domain. This 


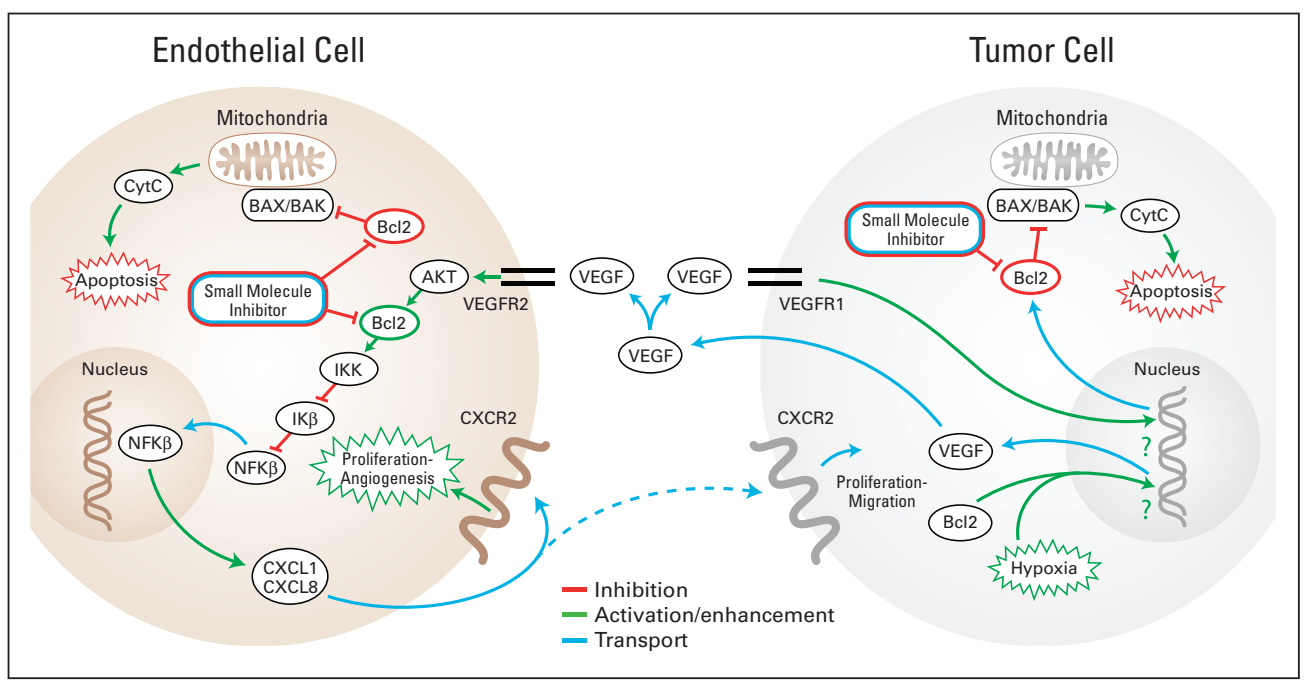

Fig 1. Role of Bcl-2 in tumor cell and endothelial cell apoptosis and survival. Diagram depicts the involvement of $\mathrm{Bcl}-2$ in tumor cell and endothelial cell function, as well as in the regulation of cross-talks between the two cell types. Bcl-2 is a pivotal checkpoint in the apoptotic pathway, inhibiting the proapoptotic actions of Bax and Bak. Both Bcl-2 expression and hypoxia may result in vascular endothelial growth factor (VEGF) production, which is secreted by the tumor cell. Endogenous VEGF can bind to VEGF receptor 1 (VEGFR1) on tumor cells sending a prosurvival signal, upregulating Bcl-2 production, or can also bind to VEGFR2 on endothelial cells, promoting cell survival and stimulating proliferation and angiogenesis via $\mathrm{Bcl}-$ 2-dependent pathways.

hydrophobic groove is called the $\mathrm{BH} 3$-binding domain. In general terms, these domains define the functionality of three groups within the Bcl-2 family: two groups of either proapoptotic or antiapoptotic effector molecules bearing multiple $\mathrm{BH}$ domains and one group of facilitator or potentiator molecules bearing only the $\mathrm{BH} 3$ domain (BH3-only proteins;Fig 2). The proapoptotic effectors Bax and Bak form oligomeric pores in the mitochondrial membrane that allow egress of apoptotic signaling molecules, whereas the antiapoptotic effectors Bcl-2, Bcl- $\mathrm{x}_{\mathrm{L}}, \mathrm{Mcl}-1$, and Bfl-1/A1 bind to Bax or Bak and inhibit functional oligomerization. The proapoptotic BH3-only molecules may interact with the effector molecules to promote pore formation either by competitively inhibiting $\mathrm{Bcl}-2 / \mathrm{Bcl}-\mathrm{x}_{\mathrm{L}} / \mathrm{Mcl}-1$, binding to $\mathrm{Bax} / \mathrm{Bak}$, or by directly promoting Bax/Bak oligomerization. ${ }^{6,8}$ There are a number of models, variations on the above theme, proposed to explain the interaction of these proteins and how, or even whether, they induce apoptosis signaling via the mitochondria. Ex-

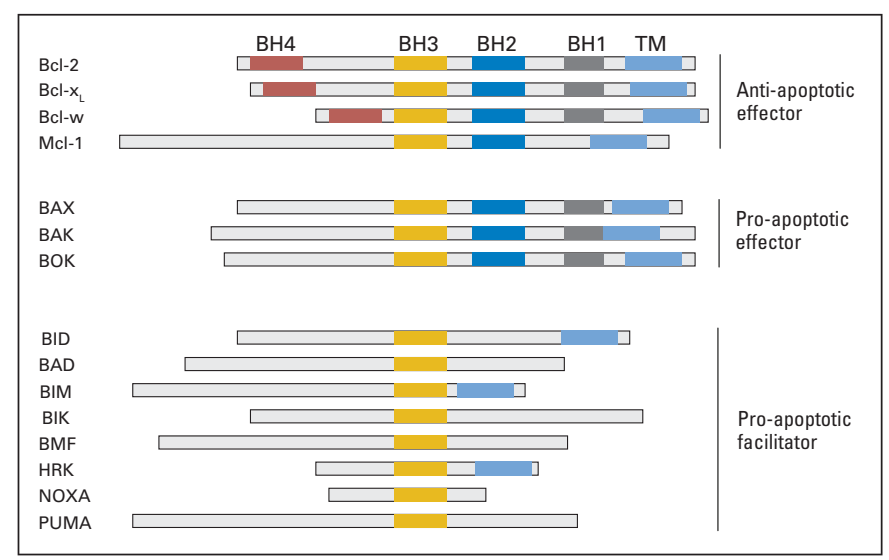

Fig 2. Bcl-2 family of proteins. This is a nonexhaustive list of the $\mathrm{Bcl}-2$ family of proteins, showing the conserved $\mathrm{Bcl}-2$ homology $(\mathrm{BH})$ domains, the transmembrane domains (TM), and the three primary classes of molecular activity. Bcl-2, $\mathrm{Bcl}-\mathrm{x}_{\mathrm{L}}, \mathrm{Mcl}-1$, and $\mathrm{Bcl}-\mathrm{w}$ represent the major molecules in the antiapoptotic class of effector molecules. Bax, Bak, and Bok represent the proapoptotic effector molecules, lacking $\mathrm{BH} 4$ domain. The proapoptotic facilitator molecules bear only the $\mathrm{BH} 3$ domain and may lack the transmembrane domain. Sizes are representative and drawn to approximate scale relative to molecular weight. actly how this happens is unclear in real cellular models at this time (see Skommer et $\mathrm{al}^{6}$ for further discussion).

\section{BCL-2: ROLE IN ANGIOGENESIS AND TUMOR STATUS}

Angiogenesis is the mechanism by which blood vessels form from existing vasculature. ${ }^{9}$ It is fundamental to normal growth and development and as part of the physiologic response to wounding. Hyperplastic cell growth both encourages and requires formation of new blood vessels, as evidenced by the generally high vascularity of tumors. Indeed, beyond 1- to 2-mm size, tumors cannot sustain expansion without induction of angiogenesis. Simple diffusion of nutrients is clearly insufficient to maintain tumor growth. ${ }^{10}$ Three of the primary activators of angiogenesis are vascular endothelial growth factor (VEGF), CXCL1 (growth-related oncogene, GRO-alpha), and CXCL8 (interleukin-8), promoting endothelial cell survival and proliferation. ${ }^{11,12}$

The involvement of $\mathrm{Bcl}-2$ as a proangiogenic signaling molecule is only now becoming clearer for both tumor cells and vascular endothelial cells (Fig 1). Indeed it has long been recognized that both $\mathrm{Bcl}-2$ and Bfl-1/A1 are mediators of protection for endothelial cells, ${ }^{13}$ although Bfl-1/A1 seems to perform a rapid, and more transient, function than $\mathrm{Bcl}-2$, potentially related to inflammatory response. ${ }^{13,14}$ Although modulation of Bcl-2 in endothelial cells has been shown to affect angiogenesis in vitro and in vivo (discussed further in this paragraph and in Bcl-2 Inhibitors as Antiangiogenic Agents), little is known about the molecular mechanisms involved. Stimulation of the VEGF pathway results in increased expression of Bcl-2 in both tumor cells ${ }^{15}$ and endothelial cells. ${ }^{13,16,17} \mathrm{Bcl}-2$ upregulation in turn increases VEGF expression in endothelial cells and in tumor cells of various lineages. ${ }^{18-20}$ Notably, Bcl-2 upregulation induces expression of the proangiogenic chemokines CXCL1 and CXCL8 through activation of the NF-kB signaling pathway in endothelial cells. ${ }^{16,21}$ It has recently been shown in human tumor biopsies that Bcl-2 is massively upregulated in head and neck squamous cell carcinoma-associated endothelial cells compared with endothelial cells in normal oral mucosa. ${ }^{20}$ In this study, it was also demonstrated in vivo that factors secreted by endothelial cells, in response to modulation of Bcl-2 expression levels in neovascular endothelial cells, have a direct effect on tumor cell 
growth. ${ }^{20}$ Additionally, the authors showed expression of VEGF to be significantly attenuated in vitro by small inhibitory RNA directed against $\mathrm{Bcl}-2$, in both $\mathrm{Bcl}-2$ overexpressing and control endothelial cells. ${ }^{20}$ It is clear that disruption of the Bcl-2 pathway may be expected to affect angiogenesis, both directly by inhibiting function of endothelial cells and, as many cancers display increased Bcl-2 expression, by concomitant reduction in levels of endothelial-stimulating factors, such as VEGF, CXCL1, and CXCL8 (Fig 1). Recently, endotheliumtargeted $\mathrm{Bcl}-2$ overexpression was shown to induce disruption of the blood vessel architecture and induce embryonic lethality in transgenic mice. ${ }^{22}$ This effect was limited to the microvasculature and related to a reduction in endothelial apoptosis, thus directly linking Bcl-2 levels during development to angiogenic function. ${ }^{22}$

It should be noted that the clinical picture of $\mathrm{Bcl}-2$ involvement in cancer progression or patient survival is unclear, with different studies finding varying degrees of correlation between Bcl-2 expression and disease severity or prognosis, both within and between cancer types. $^{23,24}$ Moreover, there is no clear reason why Bcl-2 expression, as a negative or positive prognostic factor, should bear any relation to whether $\mathrm{Bcl}-2$ is considered as a beneficial therapeutic target. One example of this dichotomy is that of small-cell lung cancer (SCLC) or non-small-cell lung cancer (NSCLC). Meta-analysis of the data from 28 clinical studies indicated that Bcl-2 expression was associated with good prognosis in NSCLC but had no correlation with disease state in SCLC. ${ }^{25}$ Furthermore, some individual studies have indeed shown correlation between $\mathrm{Bcl}-2$ or $\mathrm{Bcl}-\mathrm{x}_{\mathrm{L}}$ expression and poor disease prognosis in NSCLC. ${ }^{26,27}$ However, in vitro and in vivo studies consistently correlate increased $\mathrm{Bcl}-2$ or $\mathrm{Bcl}-\mathrm{x}_{\mathrm{L}}$ expression with tumor aggression and tumor cell line resistance to chemotherapeutic drugs. ${ }^{28-30}$ They have further shown regression and reversal of drug resistance, by treatment with $\mathrm{Bcl}-2$ family inhibitors, in SCLC tumors and others. ${ }^{29,30}$

The disparity between tumor expression and therapeutic potential may result from varying methods of analysis, but may also be explained at the cellular level. This is illustrated by two studies. In the first, an acute lymphoblastic leukemia cell line treated with VEGF expressed a phosphorylated form of $\mathrm{Bcl}-2$, and apoptosis was reduced. ${ }^{31,32}$ The expression of nonphosphorylatable Bcl-2 in these cells prevented this antiapoptotic effect. In contrast, the same authors ${ }^{32}$ also showed that VEGF-induced phosphorylation of Bcl-2 did not protect chronic lymphoblastic leukemia cells under similar conditions. Expression levels and post-translational modification of other pro- or antiapoptotic proteins, in particular the BH3-only proteins, may also account for the apparent differences. ${ }^{33-35}$ Furthermore, inactivation of $\mathrm{Bcl}-\mathrm{x}_{\mathrm{L}}$ by de-amidation occurs in response to common chemotherapeutic drugs, such as cisplatin. ${ }^{36}$ With this number of variables, it is clear that simply looking at the expression level of Bcl-2 alone in a tumor is insufficient to predict the benefits of anti-Bcl-2 therapy. Profiling the expression of many specific markers within a tumor may provide a better indication for the suitability of therapies targeting individual pathways, but this analysis is not routinely performed. Accordingly, quantifiable RNA analysis of gene expression and antibody arrays or Western blot analysis of proteins could usefully supplement immunohistochemical data from tumor biopsies in future studies. Thus, at this stage, it is difficult to predict which cancers would benefit most from treatment with Bcl-2 inhibitors and in combination with which conventional therapies.

\section{BCL-2 INHIBITORS AS ANTITUMOR AGENTS}

Both internal signaling and external stimuli may alter the complex balance toward apoptosis by activation of the proapoptotic $\mathrm{BH} 3$-only molecules and subsequent inactivation of $\mathrm{Bcl}-2 / \mathrm{Bcl}-\mathrm{x}_{\mathrm{L}}$, thus tipping the balance in favor of apoptosis. Much research has been carried out attempting to exploit the $\mathrm{BH} 3$-binding permissive network toward development of $\mathrm{Bcl}-2 / \mathrm{Bcl}-\mathrm{x}_{\mathrm{L}}$ inhibitors that result in activation of $\mathrm{Bax}$ and Bak. A number of genetic and pharmacologic approaches have been used to this end. Targeting Bcl-2 family RNA has shown positive results, and oblimersen (Genasense; G3139; Genta Inc, Berkeley Heights, NJ), an anti-Bcl-2 antisense oligonucleotide, has reached phase III clinical trials in combination therapy. ${ }^{37}$ Peptide-based drugs have also been shown both to attenuate $\mathrm{Bcl}-2$ activity ${ }^{38}$ and to activate Bax. ${ }^{8}$ However, nonpeptidic small-molecule inhibitors of signaling pathways are likely to remain developmental drugs of choice for the short to medium term, particularly because of the inherent low antigenicity of nonprotein organic compounds. In addition, the ease and plasticity of molecular modification allows ready tailoring of putative drugs. This last allows manipulation of compounds to aid routespecific delivery, increase bioavailability, increase target affinity, and, hopefully, to reduce patient drug load. This is a relatively new area for Bcl-2 inhibitors, and currently few compounds have been under developmental and clinical study since the start of the decade. Only within the last 6 to 12 months have publications appeared on a newer, larger group of compounds. The established compounds with available experimental data are discussed next in the context of cancer and angiogenesis. In this review, these compounds have been categorized as derived from natural sources (see "From Nature") or compounds that were designed in laboratories (see "From Desktop to Benchtop to Bedside").

\section{From Nature}

The first drugs to be examined for therapeutic potential in many diseases are generally pre-existing compounds that may be in use for ostensibly unrelated purposes. Even where they have been examined for anticancer activity, their molecular targets are rarely known in advance. This has certainly been true for Bcl-2 inhibitors. The health benefits of green and black tea polyphenols, in particular catechins and theaflavins, have been touted as almost the nearest equivalent to natural cure-alls. Indeed they do seem to have remarkably broad therapeutic properties according to the literature ${ }^{39-42}$ and are commonly listed as small-molecule Bcl-2 inhibitors in cancer-related publications. Work from the Burnham Institute for Medical Research, using nuclear magnetic resonance structural data and binding displacement studies, provided clear evidence of binding between green or black tea polyphenols and $\mathrm{Bcl}-2$ and $\mathrm{Bcl}-\mathrm{x}_{\mathrm{L}}{ }^{43,44}$ They also readily induce apoptosis in tumor cells in vitro and in vivo. ${ }^{45-48}$ However, tea polyphenols, and in particular the major active component epigallocatechin-3-gallate (EGCG; Fig 3F, Table 1), have been shown to act as highly specific ligands for a variety of cellular pathways other than those of Bcl-2. These include inhibition of platelet-derived growth factor receptor ligand binding, ${ }^{71}$ tyrosine phosphorylation of the Her/Neu epidermal growth factor receptor, ${ }^{72}$ and signaling by the metastasis-associated $67-\mathrm{kDa}$ laminin receptor. ${ }^{73}$ Expression of this last receptor conferred specific responsiveness on cancer cells to the growth inhibitory effects of EGCG and bound EGCG with a Kd of 39.9 nmol/L. ${ }^{73}$ In addition to these extracellular targets, tea polyphenols 


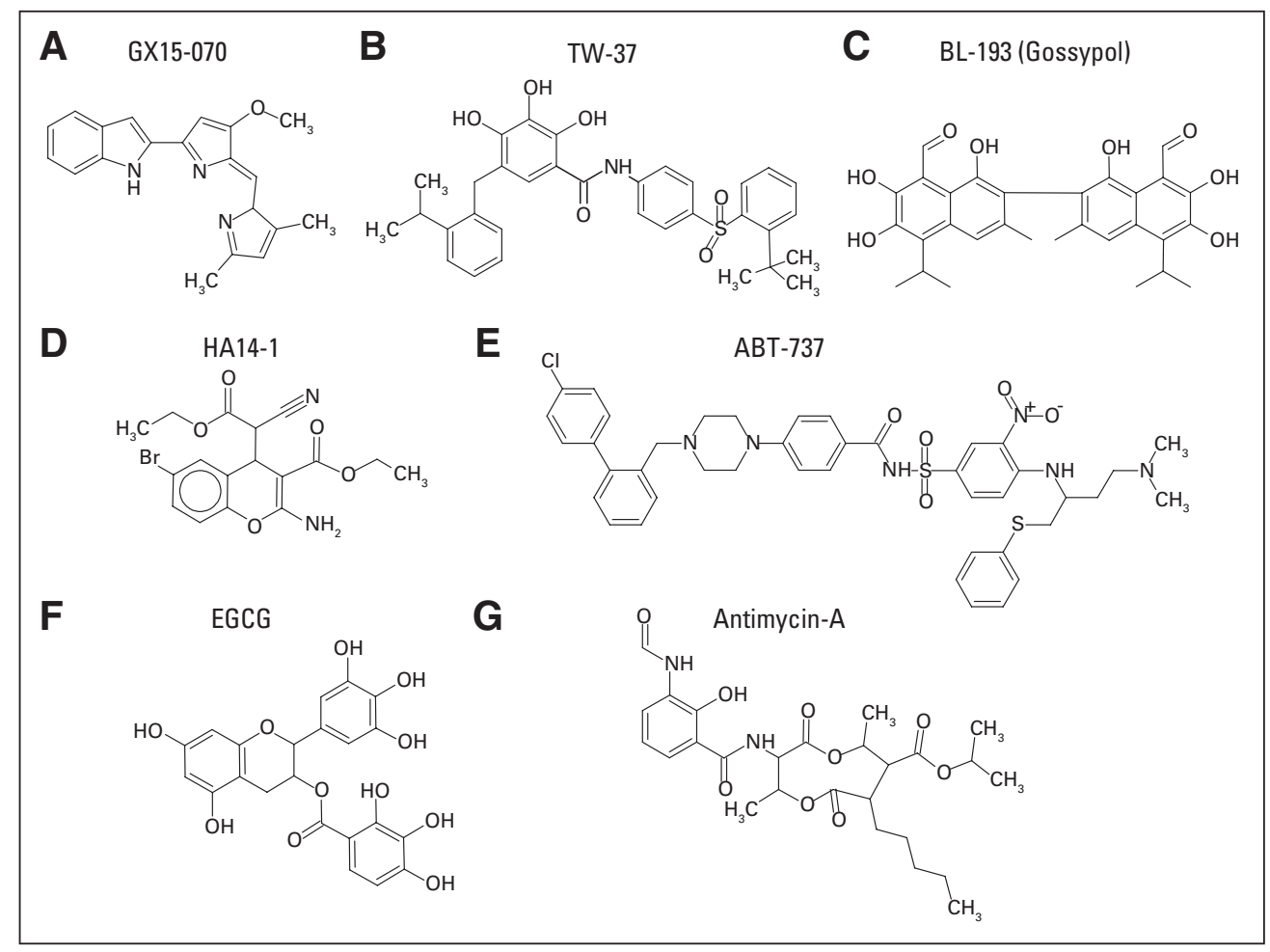

Fig 3. Small-molecule inhibitors of $\mathrm{Bcl}-2$ family proteins. Chemical structures of the various small-molecule inhibitors of $\mathrm{Bcl}-2$ discussed in this review. EGCG, epigallocatechin-3-gallate.

(EGCG in particular) have been shown to bind to, or directly affect, the pathways of a number of signaling molecules, including cyclooxygenase and retinoblastoma protein. ${ }^{74,75}$ These all may have equal claim, alongside Bcl-2, to be the cancer cell inhibitory targets for this class of compounds. Therefore, although tea polyphenols remain an exciting area for investigation as active antitumor-cell drugs, it is difficult to accurately describe them as primarily acting via the Bcl2 pathway.

The other major natural derivative in this class, gossypol, was isolated from the cotton plant and has been well studied as a contra- ceptive for human males. ${ }^{76}$ However, gossypol, and in particular the (-)-gossypol enantiomer (AT-101; Ascenta Therapeutics Inc, Malvern, PA; Fig 3C, Table 1), was found to bind to Bcl-2 and $\mathrm{Bcl}-\mathrm{x}_{\mathrm{L}}$ through fluorescence-based ligand competition assay and nuclear magnetic resonance binding analysis. ${ }^{49}$ In contrast with tea polyphenols, there is a preponderance of evidence to suggest that the $\mathrm{Bcl}-2$ family is a specific target of gossypol for induction of apoptosis. Although gossypol does bind to other molecules, calcineurin, glutathione-s-transferase, and lactate dehydrogenase with good affinity, targeting the Bcl-2 pathways seems the most likely mechanism for

\begin{tabular}{|c|c|c|c|c|c|c|c|}
\hline \multirow[b]{2}{*}{$\begin{array}{l}\text { Small-Molecule } \\
\text { Inhibitor }\end{array}$} & \multirow[b]{2}{*}{$\begin{array}{l}I_{50} \text { Range } \\
(\mu \mathrm{M})^{*}\end{array}$} & \multicolumn{3}{|c|}{ Binding Coefficientst } & \multicolumn{2}{|c|}{ Reported Range In Vivo } & \multirow[b]{2}{*}{ Studies (first author) } \\
\hline & & $\mathrm{Bcl}-2$ & $\mathrm{Bcl}-\mathrm{x}_{\mathrm{L}}$ & Mcl-1 & Therapeutic & $\begin{array}{c}\text { MTD } \\
(\mathrm{mg} / \mathrm{kg} \text { qd })\end{array}$ & \\
\hline Gossypol & $2.2-13.2$ & $0.28-50$ & $0.4-3.03$ & 1.75 & $5-30 \mathrm{mg} / \mathrm{kg}$ & $3 \times 40$ & $\begin{array}{l}\text { Kitada }^{49} \text { Zhang, }^{50} \text { Mohammadd }^{51} \text { Wolter, }^{52} \text { Bauer, }_{,}{ }^{29} \\
\text { Xu, }{ }^{53} \text { Zeitlin, }{ }^{55} \text { Van Poznak } \\
{ }^{57}\end{array}$ \\
\hline HA14-1 & $5-20$ & $0.9-100$ & NA & NA & $\begin{array}{l}400 \mathrm{nmol} \text { (approximately } \\
136 \mu \mathrm{g} \text { )/mouse }\end{array}$ & NA & van Delft, ${ }^{7}$ Wang, ${ }^{54}$ Lickliter, $^{56}$ Chen, $^{58}$ Manero ${ }^{59}$ \\
\hline TW-37 & $0.2-0.29$ & $0.12-0.7$ & 1.11 & 0.26 & $3-30 \mathrm{mg} / \mathrm{kg}$ qd & $3 \times 40$ & Wang, ${ }^{60}$ Mohammad, ${ }^{61}$ Zeitlin, $^{55}$ Verhaegen ${ }^{62}$ \\
\hline GX15-070 & 1.7 & $1.11 \ddagger$ & $4.69 \ddagger$ & $2.9 \ddagger$ & $0.25-3 \mathrm{mg} / \mathrm{kg} / \mathrm{d}$ iv & NA & Zhai, ${ }^{43}$ Campàs, ${ }^{63}$ Nguyen ${ }^{64}$ \\
\hline ABT-737 & $0.13-5$ & 0.12 & 0.064 & $>20$ & $20-100$ mg/kg/ip qd & NA & van Delft, ${ }^{7}$ Oltersdorf, ${ }^{30}$ Konopleva, ${ }^{65}$ Zhai $^{43}$ \\
\hline EGCG & $20-65$ & 0.45 & 0.59 & 0.92 & $1.5 \mathrm{mg} / \mathrm{d}$ ip & NA & Yang, ${ }^{45}$ Pan, ${ }^{46}$ Navarro-Perán, ${ }^{47}$ Jung $^{48}$ \\
\hline $\begin{array}{l}\text { Antimycin } A \text { and } \\
\text { derivatives }\end{array}$ & $0.37-0.7$ & $0.82-100$ & 2.7 & 2.51 & $2 \mathrm{mg} / \mathrm{kg}$ ip & NA & 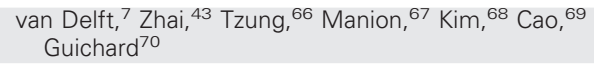 \\
\hline \multicolumn{8}{|c|}{$\begin{array}{l}\text { NOTE. Values are representative ranges of activities for drugs in a variety of cells and conditions. Lack of consistent and comparable studies between various } \\
\text { compounds makes more exact reporting of values difficult to interpret. } \\
\text { Abbreviations: IC } \\
\text { intraperitoneally. } \\
\text { "Refers to reported } I_{50} \text {, half maximal inhibitory concentration; MTD, maximum-tolerated dose; qd, each day; NA, not available at time of writing; iv, intravenously; ip } \\
\text { tDetermined using varying competitive binding assays. } \\
\text { fData for GX15, derivative of clinically tested GX15-070. }\end{array}$} \\
\hline
\end{tabular}


induction of apoptosis. ${ }^{77-79}$ Higher Bcl-2 expression levels in tumor cell lines have been correlated with increased apoptotic efficacy of gossypol. ${ }^{80,81}$ Notably, in addition to a direct Bcl-2 inhibitory action, gossypol modulates Bcl-2 family balance by downregulating the antiapoptotic members of the $\mathrm{Bcl}-2$ family and upregulating the proapoptotic members in a concentration and cell-line specific manner. ${ }^{50,82,83}$ As a single agent, the (-)-gossypol enantiomer has shown encouraging efficacy in vivo in a head and neck cancer model. ${ }^{52}(-)$-Gossypol has also been shown to overcome cisplatin resistance in vitro in a head and neck cancer line. ${ }^{29}$ Two recent in vivo studies have reported a cooperative effect for administration of $(-)$-gossypol in conjunction either with chemotherapy (cyclophosphamide, doxorubicin, vincristine, and prednisolone regimen) or radiotherapy. ${ }^{51,53} \mathrm{~A}$ significant decrease in xenograft tumor volume (cells from a patient with clinically resistant diffuse large-cell lymphoma) was observed when animals were treated with (-)-gossypol/ cyclophosphamide, doxorubicin, vincristine, and prednisolone chemotherapy as compared with either individual treatment alone.

Mixed results were seen for racemic gossypol in phase I/II trials, but no severe toxicity was observed, except during determination of maximum-tolerated doses, where severe emesis was the doselimiting toxicity. ${ }^{57,84-86}$ Currently, phase I/II clinical trials are underway for (-)-gossypol (AT-101) in single-agent treatment of relapsed B-cell malignancy. The compound is also being assessed in combination therapy with docetaxel and prednisone for hormonerefractory prostate cancer and also with an anti-CD20 antibody, rituximab, for chronic lymphocytic leukemia (see clinical trial listing at www.cancer.gov). Two further clinical trials have been approved for relapsed/refractory SCLC and newly diagnosed glioblastoma multiforme (www.cancer.gov).

Also under development are derivatives of Antimycin A, isolated from Streptomyces. Antimycin A (Fig 3G, Table 1) is an antifungal compound and a mitochondrial poison that targets complex III of the respiratory chain and that was shown to bind to the $\mathrm{BH} 3$ binding domain of Bcl-2/Bcl- $\mathrm{x}_{\mathrm{L}} \cdot{ }^{43,66,67} \mathrm{It}$ is highly toxic in mouse models, with a single median lethal dose of $1 \mathrm{mg} / \mathrm{kg}$. ${ }^{66,68,87}$ Although a large body of literature can be found for the parent molecule, considerably less work has been published about the newer, less toxic derivatives, in particular, 2-methoxyantimycin. ${ }^{66,69,87,88}$ 2-Methoxyantimycin has been shown to function cooperatively with paclitaxel and docetaxel to induce apoptosis, whereas the parental compound, Antimycin A, displayed synergy with the topoisomerase inhibitor SN-38 in inhibiting cell growth in a human colon cancer line. ${ }^{70,87}$ If the less toxic antimycin analogs can retain activity displayed in the few available studies, they may prove to be a particularly interesting drug series.

\section{From Desktop and Benchtop to Bedside}

Inspired by the potential of natural Bcl-2 inhibitors, several research groups have developed specific inhibitors of Bcl-2. Primarily, various forms of in silico and in vitro screening of combinatorial libraries, for best-fit compounds, have resulted in Bcl-2 inhibitors of varying capacity and high affinity for one or more of the Bcl-2 family of proteins. HA14-1 (Fig 3D, Table 1) was the first Bcl-2-binding ligand to be discovered using these computer-based screening strategies using the predicted structure of Bcl-2. ${ }^{54}$

Both synergistic and additive effects of HA14-1, with other chemotherapeutic compounds, contributed to reversal of drug resistance in vitro in a broad variety of cell lines and treatment regimens. ${ }^{56,58,89-92}$
Notably, the order of treatment in a combination regimen made a profound difference in the final effect. HA14-1 acts as a radiosensitizer on LNCaP and PC3 prostate cancer cell lines with or without overexpression of Bcl-2. Synergy was only seen in the PC3 cells when HA14-1 was administered after exposure to gamma radiation, and not in the reverse order. ${ }^{91}$ In glioblastoma cells, a 1-hour pretreatment with HA14-1 sensitized the cells to radiation in a Bcl-2, but not $\mathrm{Bcl}-\mathrm{x}_{\mathrm{L}}$, dependent manner. ${ }^{59}$ Skommer et $\mathrm{al}^{90}$ found synergy between HA14-1 and dexamethasone or doxorubicin, but not vincristine, in inhibiting B-cell lymphoma tumor cell proliferation. They observed that for HA14-1 and doxorubicin, synergistic inhibition was seen only when the Bcl-2 inhibitor was administered 24 hours before the conventional chemotherapeutic drugs, and antagonism was seen if they were administered simultaneously. In combination with the cyclindependent kinase (CDK) inhibitor flavopiridol, HA14-1 displays a similar synergy, but in this instance, only when the Bcl-2 inhibitor is administered after the CDK inhibitor. ${ }^{93}$ It is noteworthy that the precise order of administration of HA14-1 in radiation, doxorubicin, or flavopiridol studies was important for enhancement of the inhibitory effect of HA14-1. Although not reported for all the Bcl-2 smallmolecule inhibitors, most classes of drugs display administration order preferences for optimal cooperation with other therapeutic agents. The varying results, described above, for HA14-1 in combination therapy with radiation or chemotherapeutics may be due to tumor-specific differences in target expression (Bcl-2/Bcl- $\left.\mathrm{x}_{\mathrm{L}} / \mathrm{Mcl}-1\right)$ or modulation of those proteins by whichever therapy is administered first.

Other small-molecule inhibitors of Bcl-2 began to appear after HA14-1, in particular TW-37 (TW37) and ABT-737. Both TW-37 and ABT-737 improve on HA14-1 in efficacy, having nanomolar affinities for Bcl-2. However, only TW-37 has nanomolar to low micromolar affinities for all of the major antiapoptotic members of the Bcl-2 family of proteins. TW-37 (Fig 3B, Table 1) represents a new class of pan-Bcl-2 protein family inhibitor. It is a $\mathrm{BH} 3$ mimetic developed by rational structural design using a computer-based modeling strategy. ${ }^{60,61}$ Apoptosis was shown to be the primary mechanism for the growth-inhibitory properties of TW-37 in the prostate cancer cell line PC3. ${ }^{60} \mathrm{TW}-37$ has also been shown to effectively inhibit growth of Kaposi's sarcoma (SLK), breast cancer (MCF-7), and prostate cancer (LnCap) cell lines without inhibitory effects on human dermal fibroblasts. ${ }^{55}$

Melanoma is particularly resistant to conventional chemotherapies. ${ }^{94}$ TW-37 was found to be effective against melanoma-derived tumors when jointly administered with the mitogen-activated protein kinase kinase (MEK) inhibitors U0126 or CL-1040 and, to a lesser extent, as single agent both in vivo and in vitro. ${ }^{62}$ The rationale for coadministration was that some melanomas respond poorly to mitogen-activated protein kinase inhibition, possibly through ERKmediated upregulation of the antiapoptotic Bcl-2 family of proteins. Using lentiviral-driven inhibitory RNA, the Soengas group produced a series of isogenic melanoma cell lines deficient in specific molecules of the apoptosis pathway. They identified $\mathrm{Bcl}-2, \mathrm{Mcl}-1$, and $\mathrm{Bcl}-\mathrm{x}_{\mathrm{L}}$ as integral components of resistance to MEK inhibition. ${ }^{62}$ They also showed synergistic inhibition of melanoma cell growth by TW-37 and the MEK inhibitors in vitro. Notably, in vivo coadministration significantly inhibited xenografted melanoma tumor growth when compared with either agent alone. ${ }^{62}$ 
In an initial study by Oltersdorf et al, ${ }^{30} \mathrm{ABT}-737$ (Fig 3E, Table 1) was shown to bind $\mathrm{Bcl}-2, \mathrm{Bcl}-\mathrm{x}_{\mathrm{L}}$, and Bcl-w with high affinity $(\mathrm{Ki} \leq 1 \mathrm{nmol} / \mathrm{L})$, but to have extremely low affinity for Mcl-1, $\mathrm{Bcl}-\mathrm{b}$, and $\mathrm{A} 1$. Indeed, the low affinity for Mcl-1 has defined part of the research into this compound, as the drug efficacy is greatly attenuated in the presence of that protein. ABT-737 was effective in delaying growth of tumors overexpressing Bcl-2. In contrast, tumors transduced with vectors inducing Mcl-1 overexpression were highly refractory to the drug. ${ }^{95}$ Additionally, ABT-737 induced thrombocytopenia in mice in a transient and reversible manner but was nontoxic to hematopoietic progenitor cells, including megakaryocytes. ${ }^{65,96,97}$ This was shown to occur via direct inhibition of platelet $\mathrm{Bcl}-\mathrm{x}_{\mathrm{L}}$ by ABT-737, preventing binding of $\mathrm{Bcl}-\mathrm{x}_{\mathrm{L}}$ to Bak and inducing Bak-mediated platelet apoptosis. ${ }^{97}$ Recently, Chen et $\mathrm{al}^{98}$ have shown that selective downregulation of Mcl-1, either by CDK inhibitors such as roscovitine or by gene silencing, synergistically increases the sensitivity of human leukemia cells to ABT-737-induced apoptosis.

Given these issues, it is notable that ABT-737 is a highly active drug in several models. It has shown antitumor efficacy, as a single agent administered intraperitoneally, in two models of lung cancer using cell lines with known sensitivity to the compound and also in models of leukemia. ${ }^{30,65}$ In chronic myelogenous leukemia, the Bcr/ $\mathrm{Abl}$ pathway promotes leukemogenesis, but the $\mathrm{Bcr} / \mathrm{Abl}$ inhibitor (imatinib; Gleevec, Novartis Pharmaceuticals Corp, East Hanover, $\mathrm{NJ}$ ) induces apoptosis in affected cells via a Bcl-2/Bcl- $\mathrm{x}_{\mathrm{L}}$-mediated pathway. ${ }^{99}$ Coadministration of ABT-737 and imatinib to Bim/Bad double knockout Bcr/Abl-positive cells enhanced apoptosis as compared with either drug alone. ${ }^{100}$ Thus ABT-737 seems to compensate for the loss of the $\mathrm{BH} 3$-only proteins Bim or Bad. It remains to be seen whether ABT737 moves on to clinical trial, although a structurally related, orally available analog, ABT-263, is indeed entering phase I/II clinical trials for lymphocytic leukemia and SCLC ${ }^{101}$ (www.cancer.gov).

Another small-molecule inhibitor of all the major Bcl-2 antiapoptotic family proteins, GX15-070 (Obatoclax; Fig 3A; Table 1), was developed by Gemin X Biotechnologies Inc. (Montreal, Quebec, Canada). Although it was the first of the specifically designed Bcl-2 small-molecule inhibitor drugs to be approved in the United States for four clinical trials (www.cancer.gov) and has been under patent since 2002, little has yet been published on this compound. In one study by Campas et al, ${ }^{63}$ GX15-070 displayed a mean half maximal effective concentration of $1.7 \pm 0.1 \mu \mathrm{mol} / \mathrm{L}$ in isolated cell lines, ranging over a 48 -hour period. However, this calculation of activity excluded two lines of 11 , which were considered resistant to GX15-070. Therefore, reliable determination of the activity of this drug within this class of tumors must await other confirmatory studies at this time. Additive effects were reported in combination with fludarabine and chlorambucil administered with $0.5 \mu \mathrm{mol} / \mathrm{L}$ of GX15-070. However, synergy was observed for GX15-070 administered with the proteasome inhibitor, bortezomib, and the order of administration was not reported to alter synergistic efficacy. ${ }^{64,102}$ In three mantle-cell lymphoma lines studied, apoptotic concentrations of GX15-070 were able to inhibit binding of immunoprecipitated $\mathrm{Mcl}-1$ and $\mathrm{Bcl}-\mathrm{x}_{\mathrm{L}}$ to Bak, resulting in mitochondrial depolarization and caspase-3 activation. The synergistic effects of GX15-070 with bortezomib on cytotoxicity in tumor cells were attributed in large part to inhibition of the Mcl$1 /$ Bak interaction. Interestingly, they were also attributed to the in- hibitory effects of GX15-070 on Mcl-1 expression, which may have countered the strong upregulation of Mcl-1 expression induced by bortezomib treatment. ${ }^{64,102}$

\section{BCL-2 INHIBITORS AS ANTIANGIOGENIC AGENTS}

As discussed previously, Bcl-2 is intimately involved with angiogenesis through modulation of both endothelial and tumor cell signaling. Additionally, Bcl-2 inhibitors may directly induce apoptosis in angiogenically active endothelial cells in vitro, in similar fashion to their effect on tumor cells, and endothelial cell-specific apoptosis can disrupt neovascularization in vivo. ${ }^{55,103}$ Therefore, $\mathrm{Bcl}-2$ and its related signaling network becomes a logical target for antiangiogenic cancer therapy (Fig 1). There is an emerging body of literature on the in vivo antiangiogenic effect of inhibition of the Bcl-2 family of proteins. Notably, most of what is available has been presented as unquantified immunohistochemical data. However, direct effects of Bcl-2 inhibition have been quantified in at least one study, which reported a significant reduction in microvessel vessel density after TW-37 treatment in a humanized in vivo model of angiogenesis. ${ }^{55}$ Of other studies, the antiangiogenic effects of EGCG have been demonstrated, including a significant reduction in microvessel density within xenografted ovarian cancer cell tumors and colon cancer tumors. ${ }^{48,104}$ However, as discussed previously, it may be pre-emptive to use EGCG as an example of an inhibitor inducing apoptosis solely through effects on Bcl-2. (-)Gossypol has been shown to have potential antiangiogenic efficacy in vivo when administered in conjunction with radiotherapy, although without quantification of the reported changes in vessel density. ${ }^{53}$ In total, these reports suggest that $\mathrm{Bcl}-2$-dependent vasculature may indeed be targeted, in vivo, by small-molecule inhibitors of Bcl-2. Broadening the scope of literature search, two groups have published studies using antisense oligonucleotides to inhibit $\mathrm{Bcl}-2$ expression in melanoma or prostate cancer cells transfected with $\mathrm{Bcl}-2 .{ }^{105,106}$ Anai et al ${ }^{106}$ observed a reduction in microvessel density when the same cells were implanted as xenografts. Together, the work published to date suggests that $\mathrm{Bcl}-2$ inhibition, whether by pharmacologic or genetic means, may potentially inhibit angiogenesis toward a therapeutic end.

\section{SUMMARY AND IMPLICATIONS}

There is an expanding industry devoted toward inhibiting various components of the Bcl-2 pathway using designer small-molecule drugs (mw approximately 400 to 800 ). These newly developed or identified compounds not only provide us with novel therapeutic approaches to cancer treatment but also deliver new tools for the analysis of the many functions of the Bcl-2 family of proteins. With our knowledge of the Bcl-2 family expanding rapidly, this specific avenue of pharmaceutical development is unlikely to slow down in the near future. It is strengthened by the proven therapeutic efficacy of both older and more recent pharmacologic agents in vivo, particularly (-)-gossypol and ABT-737, and the utility of the same compounds for dissection of apoptotic and angiogenic pathways. 
Possibly the most useful similarities shared by these drugs are their low overall toxicities in comparison with conventional cancer therapeutics and, often, their ability to synergize with those therapeutics to inhibit tumor cell survival. Although Bcl-2 smallmolecule inhibitors are not magic bullets, they do provide a new weapon for the existing anticancer arsenal. Perhaps in sniping at new sites of blood vessel growth around metastatic sites, or used in barrage with the combined force of traditional chemotherapeutics or radiotherapy, they might prove to be efficient and safe for patients with cancer. However applied, small-molecule inhibitors of Bcl-2 have marked potential for cancer research and treatment.
AUTHORS' DISCLOSURES OF POTENTIAL CONFLICTS OF INTEREST

The author(s) indicated no potential conflicts of interest.

\section{AUTHOR CONTRIBUTIONS}

Conception and design: Benjamin D. Zeitlin, Jacques E. Nör

Manuscript writing: Benjamin D. Zeitlin, Isaac J. Zeitlin, Jacques E. Nör Final approval of manuscript: Benjamin D. Zeitlin, Isaac J. Zeitlin, Jacques E. Nör

\section{REFERENCES}

1. Wang D, Lippard SJ: Cellular processing of platinum anticancer drugs. Nat Rev Drug Discov 4:307-320, 2005

2. Rabik CA, Dolan ME: Molecular mechanisms of resistance and toxicity associated with platinating agents. Cancer Treat Rev 33:9-23, 2007

3. Lee $\mathrm{KH}$, Im SA, Oh DY, et al: Prognostic significance of bcl-2 expression in stage III breast cancer patients who had received doxorubicin and cyclophosphamide followed by paclitaxel as adjuvant chemotherapy. BMC Cancer 7:63, 2007

4. Khor LY, Moughan J, Al-Saleem T, et al: $\mathrm{Bcl}-2$ and bax expression predict prostate cancer outcome in men treated with androgen deprivation and radiotherapy on radiation therapy oncology group protocol 92-02. Clin Cancer Res 13:35853590, 2007

5. Contu PC, Contu SS, Moreira LF: Bcl-2 expression in rectal cancer. Arq Gastroenterol 43:284287, 2006

6. Skommer J, Wlodkowic D, Deptala A: Larger than life: Mitochondria and the bcl-2 family. Leuk Res 31:277-286, 2007

7. van Delft MF, Huang DC: How the bcl-2 family of proteins interact to regulate apoptosis. Cell Res 16:203-213, 2006

8. Oh KJ, Barbuto S, Pitter K, et al: A membranetargeted BID BCL-2 homology 3 peptide is sufficient for high potency activation of BAX in vitro. J Biol Chem 281:36999-37008, 2006

9. Bikfalvi $A$ : Angiogenesis: Health and disease. Ann Oncol 17:x65-70, 2006 (suppl 10)

10. Carmeliet $P$, Jain RK: Angiogenesis in cancer and other diseases. Nature 407:249-257, 2000

11. Mehrad B, Keane MP, Strieter RM: Chemokines as mediators of angiogenesis. Thromb Haemost 97:755-762, 2007

12. Singh S, Sadanandam A, Singh RK: Chemokines in tumor angiogenesis and metastasis. Cancer Metastasis Rev 26:453-467, 2007

13. Gerber HP, Dixit V, Ferrara N: Vascular endothelial growth factor induces expression of the antiapoptotic proteins bcl-2 and $\mathrm{A} 1$ in vascular endothelial cells. J Biol Chem 273:13313-13316, 1998

14. Karsan A, Yee E, Kaushansky K, et al: Cloning of human bcl-2 homologue: Inflammatory cytokines induce human A1 in cultured endothelial cells. Blood 87:3089-3096, 1996

15. Pidgeon GP, Barr MP, Harmey JH, et al: Vascular endothelial growth factor (VEGF) upregulates BCL-2 and inhibits apoptosis in human and murine mammary adenocarcinoma cells. $\mathrm{Br} \mathrm{J}$ Cancer 85:273-278, 2001
16. Nör JE, Christensen J, Mooney DJ, et al: Vascular endothelial growth factor (VEGF)-mediated angiogenesis is associated with enhanced endothelial cell survival and induction of bcl-2 expression. Am J Pathol 154:375-384, 1999

17. Cai J, Ahmad S, Jiang WG, et al: Activation of vascular endothelial growth factor receptor-1 sustains angiogenesis and bcl-2 expression via the phosphatidylinositol 3-kinase pathway in endothelial cells. Diabetes 52:2959-2968, 2003

18. Biroccio A, Candiloro A, Mottolese M, et al: $\mathrm{Bcl}-2$ overexpression and hypoxia synergistically act to modulate vascular endothelial growth factor expression and in vivo angiogenesis in a breast carcinoma line. FASEB J 14:652-660, 2000

19. Iervolino $A$, Trisciuoglio $D$, Ribatti $D$, et al: $\mathrm{Bcl}-2$ overexpression in human melanoma cells increases angiogenesis through VEGF mRNA stabilization and HIF-1-mediated transcriptional activity. FASEB J 16:1453-1455, 2002

20. Kaneko T, Zhang Z, Mantellini M, et al: Bcl-2 orchestrates a cross-talk between endothelial and tumor cells that promotes tumor growth. Cancer Res 67:9685-9693, 2007

21. Karl E, Warner K, Zeitlin B, et al: Bcl-2 acts in a proangiogenic signaling pathway through nuclear factor-kappaB and CXC chemokines. Cancer Res 65:5063-5069, 2005

22. Duval H, Johnson N, Li J, et al: Vascular development is disrupted by endothelial cell-specific expression of the anti-apoptotic protein bcl-2. Angiogenesis 10:55-68, 2007

23. Hadar T, Shvero J, Yaniv E, et al: Expression of p53, ki-67 and bcl-2 in parathyroid adenoma and residual normal tissue. Pathol Oncol Res 11:45-49, 2005

24. Daidone MG, Veneroni $S$, Benini $E$, et al: Biological markers as indicators of response to primary and adjuvant chemotherapy in breast cancer. Int J Cancer 84:580-586, 1999

25. Martin B, Paesmans $M$, Berghmans $T$, et al: Role of bcl-2 as a prognostic factor for survival in lung cancer: A systematic review of the literature with meta-analysis. Br J Cancer 89:55-64, 2003

26. Karczmarek-Borowska B, Filip A, Wojcierowski $J$, et al: Estimation of prognostic value of bcl-xL gene expression in non-small cell lung cancer. Lung Cancer 51:61-69, 2006

27. Brooks KR, To K, Joshi MB, et al: Measurement of chemoresistance markers in patients with stage III non-small cell lung cancer: A novel approach for patient selection. Ann Thorac Surg 76: 187-193, 2003; discussion 193

28. Choi J, Choi K, Benveniste EN, et al: Bcl-2 promotes invasion and lung metastasis by inducing matrix metalloproteinase-2. Cancer Res 65:55545560, 2005
29. Bauer JA, Trask DK, Kumar B, et al: Reversal of cisplatin resistance with a $\mathrm{BH} 3$ mimetic, (-)-gossypol, in head and neck cancer cells: Role of wild-type p53 and bcl-xL. Mol Cancer Ther 4:1096-1104, 2005

30. Oltersdorf T, Elmore SW, Shoemaker AR, et al: An inhibitor of bcl-2 family proteins induces regression of solid tumours. Nature 435:677-681, 2005

31. Wang $L$, Chen $L$, Benincosa J, et al: VEGFinduced phosphorylation of bcl-2 influences $B$ lineage leukemic cell response to apoptotic stimuli. Leukemia 19:344-353, 2005

32. Wang L, Coad JE, Fortney JM, et al: VEGFinduced survival of chronic lymphocytic leukemia is independent of bcl-2 phosphorylation. Leukemia 19: 1486-1487, 2005

33. Michels J, Johnson PW, Packham G: Mcl-1. Int J Biochem Cell Biol 37:267-271, 2005

34. Nehls O, Okech T, Hsieh CJ, et al: Studies on p53, BAX and bcl-2 protein expression and microsatellite instability in stage III (UICC) colon cancer treated by adjuvant chemotherapy: Major prognostic impact of proapoptotic BAX. Br J Cancer 96:14091418, 2007

35. Puthalakath $\mathrm{H}$, Strasser A: Keeping killers on a tight leash: Transcriptional and post-translational control of the pro-apoptotic activity of BH3-only proteins. Cell Death Differ 9:505-512, 2002

36. Deverman BE, Cook BL, Manson SR, et al: $\mathrm{Bcl}-\mathrm{xL}$ deamidation is a critical switch in the regulation of the response to DNA damage. Cell 111:5162, 2002

37. Stein CA, Benimetskaya L, Mani S: Antisense strategies for oncogene inactivation. Semin Oncol 32:563-572, 2005

38. Walensky LD, Kung AL, Escher I, et al: Activation of apoptosis in vivo by a hydrocarbonstapled BH3 helix. Science 305:1466-1470, 2004

39. Sang S, Hou Z, Lambert JD, et al: Redox properties of tea polyphenols and related biological activities. Antioxid Redox Signal 7:1704-1714, 2005

40. Hsu S: Green tea and the skin. J Am Acad Dermatol 52:1049-1059, 2005

41. Vita JA: Polyphenols and cardiovascular disease: Effects on endothelial and platelet function. Am J Clin Nutr 81:292S-297S, 2005

42. Weinreb $\mathrm{O}$, Mandel $\mathrm{S}$, Amit $\mathrm{T}$, et al: Neurological mechanisms of green tea polyphenols in Alzheimer's and Parkinson's diseases. J Nutr Biochem 15:506-516, 2004

43. Zhai $D$, Jin $C$, Satterthwait AC, et al: Comparison of chemical inhibitors of antiapoptotic bcl-2family proteins. Cell Death Differ 13:1419-1421, 2006

44. Leone $M$, Zhai $D$, Sareth $S$, et al: Cancer prevention by tea polyphenols is linked to their 
direct inhibition of antiapoptotic bcl-2-family proteins. Cancer Res 63:8118-8121, 2003

45. Yang GY, Liao J, Kim K, et al: Inhibition of growth and induction of apoptosis in human cancer cell lines by tea polyphenols. Carcinogenesis 19: 611-616, 1998

46. Pan MH, Liang YC, Lin-Shiau SY, et al: Induction of apoptosis by the oolong tea polyphenol theasinensin A through cytochrome $c$ release and activation of caspase- 9 and caspase- 3 in human U937 cells. J Agric Food Chem 48:6337-6346, 2000

47. Navarro-Perán E, Cabezas-Herrera J, GarciaCanovas $F$, et al: The antifolate activity of tea catechins. Cancer Res 65:2059-2064, 2005

48. Jung YD, Kim MS, Shin BA, et al: EGCG, a major component of green tea, inhibits tumour growth by inhibiting VEGF induction in human colon carcinoma cells. Br J Cancer 84:844-850, 2001

49. Kitada S, Leone M, Sareth S, et al: Discovery, characterization, and structure-activity relationships studies of proapoptotic polyphenols targeting B-cel lymphocyte/leukemia-2 proteins. J Med Chem 46: 4259-4264, 2003

50. Zhang M, Liu H, Guo R, et al: Molecular mechanism of gossypol-induced cell growth inhibition and cell death of HT-29 human colon carcinoma cells. Biochem Pharmacol 66:93-103, 2003

51. Mohammad RM, Wang S, Aboukameel A et al: Preclinical studies of a nonpeptidic smallmolecule inhibitor of bcl-2 and bcl-X(L) [(-)-gossypol] against diffuse large cell lymphoma. Mol Cancer Ther 4:13-21, 2005

52. Wolter KG, Wang SJ, Henson BS, et al: (-)-Gossypol inhibits growth and promotes apoptosis of human head and neck squamous cell carcinoma in vivo. Neoplasia 8:163-172, 2006

53. Xu L, Yang D, Wang S, et al: (-)-Gossypol enhances response to radiation therapy and results in tumor regression of human prostate cancer. $\mathrm{Mol}$ Cancer Ther 4:197-205, 2005

54. Wang JL, Liu D, Zhang ZJ, et al: Structurebased discovery of an organic compound that binds bcl-2 protein and induces apoptosis of tumor cells. Proc Natl Acad Sci U S A 97:7124-7129, 2000

55. Zeitlin BD, Joo E, Dong Z, et al: Antiangiogenic effect of TW37, a small-molecule inhibitor of bcl-2. Cancer Res 66:8698-8706, 2006

56. Lickliter JD, Wood NJ, Johnson L, et al: HA14-1 selectively induces apoptosis in bcl-2overexpressing leukemia/lymphoma cells, and enhances cytarabine-induced cell death. Leukemia 17: 2074-2080, 2003

57. Van Poznak C, Seidman AD, Reidenberg $M M$, et al: Oral gossypol in the treatment of patients with refractory metastatic breast cancer: A phase I/II clinical trial. Breast Cancer Res Treat 66:239-248, 2001

58. Chen J, Freeman A, Liu J, et al: The apoptotic effect of HA14-1, a bcl-2-interacting small molecular compound, requires bax translocation and is enhanced by PK11195. Mol Cancer Ther 1:961-967, 2002

59. Manero F, Gautier F, Gallenne T, et al: The small organic compound HA14-1 prevents bcl-2 interaction with bax to sensitize malignant glioma cells to induction of cell death. Cancer Res 66:27572764, 2006

60. Wang G, Nikolovska-Coleska Z, Yang CY, et al: Structure-based design of potent small-molecule inhibitors of anti-apoptotic bcl-2 proteins. J Med Chem 49:6139-6142, 2006

61. Mohammad RM, Goustin AS, Aboukameel A, et al: Preclinical studies of TW-37, a new nonpeptidic small-molecule inhibitor of bcl-2, in diffuse large cell lymphoma xenograft model reveal drug action on both bcl-2 and mcl-1. Clin Cancer Res 13:22262235, 2007

62. Verhaegen M, Bauer JA, Martin de la Vega C, et al: A novel $\mathrm{BH} 3$ mimetic reveals a mitogenactivated protein kinase-dependent mechanism of melanoma cell death controlled by p53 and reactive oxygen species. Cancer Res 66:11348-11359, 2006

63. Campàs $C$, Cosialls AM, Barragan $M$, et al: $\mathrm{Bcl}-2$ inhibitors induce apoptosis in chronic lymphocytic leukemia cells. Exp Hematol 34:1663-1669, 2006

64. Nguyen M, Marcellus RC, Roulston A, et al: Small molecule obatoclax (GX15-070) antagonizes MCL-1 and overcomes MCL-1-mediated resistance to apoptosis. Proc Natl Acad Sci U S A 104:19512 19517, 2007

65. Konopleva M, Contractor $\mathrm{R}$, Tsao $\mathrm{T}$, et al: Mechanisms of apoptosis sensitivity and resistance to the BH3 mimetic ABT-737 in acute myeloid leukemia. Cancer Cell 10:375-388, 2006

66. Tzung SP, Kim KM, Basanez G, et al: Antimycin A mimics a cell-death-inducing bcl-2 homology domain 3. Nat Cell Biol 3:183-191, 2001

67. Manion MK, O'Neill JW, Giedt CD, et al: $\mathrm{Bcl}-\mathrm{XL}$ mutations suppress cellular sensitivity to antimycin A. J Biol Chem 279:2159-2165, 2004

68. Kim KM, Giedt CD, Basanez G, et al: Biophysical characterization of recombinant human bcl-2 and its interactions with an inhibitory ligand, antimycin A. Biochemistry 40:4911-4922, 2001

69. Cao X, Rodarte C, Zhang L, et al: Bcl2/bcl-xL inhibitor engenders apoptosis and increases chemosensitivity in mesothelioma. Cancer Biol Ther 6:246252, 2007

70. Guichard SM, Hua ML, Kang $P$, et al: Short hairpin RNAs targeting bcl-xL modulate senescence and apoptosis following SN-38 and irinotecan exposure in a colon cancer model. Cancer Chemother Pharmacol 60:651-660, 2007

71. Sakata R, Ueno T, Nakamura T, et al: Green tea polyphenol epigallocatechin-3-gallate inhibits platelet-derived growth factor-induced proliferation of human hepatic stellate cell line LI90. J Hepatol 40:52-59, 2004

72. Pianetti S, Guo S, Kavanagh KT, et al: Green tea polyphenol epigallocatechin-3 gallate inhibits her-2/neu signaling, proliferation, and transformed phenotype of breast cancer cells. Cancer Res 62 : 652-655, 2002

73. Tachibana $H$, Koga $K$, Fujimura $Y$, et al: $A$ receptor for green tea polyphenol EGCG. Nat Struct Mol Biol 11:380-381, 2004

74. Ahmad N, Adhami VM, Gupta S, et al: Role of the retinoblastoma ( $\mathrm{pRb}$ )-E2F/DP pathway in cancer chemopreventive effects of green tea polyphenol epigallocatechin-3-gallate. Arch Biochem Biophys 398:125-131, 2002

75. Peng G, Dixon DA, Muga SJ, et al: Green tea polyphenol (-)-epigallocatechin-3-gallate inhibits cyclooxygenase- 2 expression in colon carcinogenesis. Mol Carcinog 45:309-319, 2006

76. Coutinho EM, Athayde C, Atta G, et al: Gossypol blood levels and inhibition of spermatogenesis in men taking gossypol as a contraceptive: A multicenter, international, dose-finding study. Contraception 61:61-67, 2000

77. Ford JM, Hait WN, Matlin SA, et al: Modulation of resistance to alkylating agents in cancer cell by gossypol enantiomers. Cancer Lett 56:85-94, 1991

78. $Y u$ Y, Deck JA, Hunsaker LA, et al: Selective active site inhibitors of human lactate dehydroge- nases A4, B4, and C4. Biochem Pharmacol 62:8189, 2001

79. Baumgrass $R$, Weiwad $M$, Erdmann $F$, et al: Reversible inhibition of calcineurin by the polyphenolic aldehyde gossypol. J Biol Chem 276:4791447921, 2001

80. Oliver $\mathrm{CL}$, Bauer JA, Wolter KG, et al: In vitro effects of the $\mathrm{BH} 3$ mimetic, (-)-gossypol, on head and neck squamous cell carcinoma cells. Clin Cancer Res 10:7757-7763, 2004

81. Oliver $C L$, Miranda MB, Shangary $S$, et al: (-)-Gossypol acts directly on the mitochondria to overcome bcl-2- and bcl-X(L)-mediated apoptosis resistance. Mol Cancer Ther 4:23-31, 2005

82. Wang $X$, Wang J, Wong $S C$, et al: Cytotoxic effect of gossypol on colon carcinoma cells. Life Sci 67:2663-2671, 2000

83. Huang $Y W$, Wang LS, Chang $H L$, et al: Molecular mechanisms of (-)-gossypol-induced apoptosis in human prostate cancer cells. Anticancer Res 26:1925-1933, 2006

84. Bushunow $P$, Reidenberg MM, Wasenko J, et al: Gossypol treatment of recurrent adult malignant gliomas. J Neurooncol 43:79-86, 1999

85. Flack MR, Pyle RG, Mullen NM, et al: Oral gossypol in the treatment of metastatic adrenal cancer. J Clin Endocrinol Metab 76:1019-1024, 1993

86. Stein RC, Joseph $A E$, Matlin $S A$, et al: $A$ preliminary clinical study of gossypol in advanced human cancer. Cancer Chemother Pharmacol 30: 480-482, 1992

87. Wang $H$, Li M, Rhie JK, et al: Preclinical pharmacology of 2-methoxyantimycin A compounds as novel antitumor agents. Cancer Chemother Pharmacol 56:291-298, 2005

88. Schwartz PS, Manion MK, Emerson CB, et al: 2-methoxy antimycin reveals a unique mechanism for bcl-x(L) inhibition. Mol Cancer Ther 6:20732080, 2007

89. Sinicrope FA, Penington RC, Tang XM: Tumor necrosis factor-related apoptosis-inducing ligand-induced apoptosis is inhibited by bcl-2 but restored by the small molecule bcl-2 inhibitor, HA 14-1, in human colon cancer cells. Clin Cancer Res 10:8284-8292, 2004

90. Skommer J, Wlodkowic D, Matto $M$, et al: HA14-1, a small molecule bcl-2 antagonist, induces apoptosis and modulates action of selected anticancer drugs in follicular lymphoma B cells. Leuk Res 30:322-331, 2006

91. An J, Chervin AS, Nie A, et al: Overcoming the radioresistance of prostate cancer cells with a novel bcl-2 inhibitor. Oncogene 26:652-661, 2007

92. Dai $Y$, Rahmani M, Corey SJ, et al: A Bcr/Ablindependent, lyn-dependent form of imatinib mesylate (STI-571) resistance is associated with altered expression of bcl-2. J Biol Chem 279:34227-34239, 2004

93. Pei $X Y$, Dai $Y$, Grant $S$ : The small-molecule bcl-2 inhibitor HA14-1 interacts synergistically with flavopiridol to induce mitochondrial injury and apoptosis in human myeloma cells through a free radical-dependent and jun $\mathrm{NH}$-terminal kinasedependent mechanism. Mol Cancer Ther 3:15131524, 2004

94. Hersey P: Apoptosis and melanoma: How new insights are effecting the development of new therapies for melanoma. Curr Opin Oncol 18:189196, 2006

95. van Delft MF, Wei $A H$, Mason KD, et al: The $\mathrm{BH} 3$ mimetic ABT-737 targets selective bcl-2 proteins and efficiently induces apoptosis via Bak/Bax if mcl-1 is neutralized. Cancer Cell 10:389-399, 2006 
96. Trudel $S$, Stewart $A K, L i Z$, et al: The bcl-2 family protein inhibitor, ABT-737, has substantial antimyeloma activity and shows synergistic effect with dexamethasone and melphalan. Clin Cancer Res 13:621-629, 2007

97. Mason KD, Carpinelli MR, Fletcher JI, et al: Programmed anuclear cell death delimits platelet life span. Cell 128:1173-1186, 2007

98. Chen $\mathrm{S}$, Dai $Y$, Harada $\mathrm{H}$, et al: Mcl-1 downregulation potentiates $\mathrm{ABT}-737$ lethality by cooperatively inducing bak activation and bax translocation. Cancer Res 67:782-791, 2007

99. Ferrao PT, Frost MJ, Siah SP, et al: Overexpression of P-glycoprotein in K562 cells does not confer resistance to the growth inhibitory effects of imatinib (STI571) in vitro. Blood 102:4499-4503, 2003
100. Kuroda J, Puthalakath $H$, Cragg MS, et al: Bim and bad mediate imatinib-induced killing of $\mathrm{Bcr} / \mathrm{Abl}(+)$ leukemic cells, and resistance due to their loss is overcome by a $\mathrm{BH} 3$ mimetic. Proc Nat Acad Sci U S A 103:14907-14912, 2006

101. Lock $R$, Carol $H$, Houghton $P J$, et al: Initial testing (stage 1) of the $\mathrm{BH} 3$ mimetic ABT-263 by the pediatric preclinical testing program. Pediatr Blood Cancer 50:1181-1189, 2008

102. Pérez-Galán $P$, Roué $G$, Villamor $N$, et al: The $\mathrm{BH} 3-$ mimetic GX15-070 synergizes with bortezomib in mantle cell lymphoma by enhancing noxa-mediated activation of bak. Blood 109:4441-4449, 2007

103. Dong Z, Zeitlin BD, Song $W$, et al: Level of endothelial cell apoptosis required for a significant decrease in microvessel density. Exp Cell Res 313: 3645-3657, 2007

104. Spinella F, Rosano L, Di Castro V, et al: Green tea polyphenol epigallocatechin-3-gallate inhibits the endothelin axis and downstream signaling pathways in ovarian carcinoma. Mol Cancer Ther 5:1483-1492, 2006

105. Del Bufalo D, Trisciuoglio D, Scarsella $M$, et al: Treatment of melanoma cells with a bcl-2/bcl-xL antisense oligonucleotide induces antiangiogenic activity. Oncogene 22:8441-8447, 2003

106. Anai S, Goodison S, Shiverick K, et al: Knockdown of bcl-2 by antisense oligodeoxynucleotides induces radiosensitization and inhibition of angiogenesis in human PC-3 prostate tumor xenografts. Mol Cancer Ther 6:101-111, 2007

\section{Acknowledgment}

We thank Shaomeng Wang for his continuous support of our studies and Chris Jung for the illustration of the model.

\section{Glossary Terms}

Bcl-2: First discovered as a translocated locus [t(14;22)] in B-cell leukemias, bcl-2 is an antiapoptotic protein that protects cells from programmed cell death by preventing the activation of proapoptotic caspase proteins.

Bcl- $\mathbf{X}_{\mathrm{L}}$ : An antiapoptotic member of the Bcl-2 family of proteins, $\mathrm{Bcl}-\mathrm{x}$ is a homolog of $\mathrm{Bcl}-2$. Depending on splicing, $\mathrm{Bcl}-\mathrm{x}$ may be present either as the short $\left(\mathrm{Bcl}-\mathrm{x}_{\mathrm{S}}\right)$ or the long $\left(\mathrm{Bcl}-\mathrm{x}_{\mathrm{L}}\right)$ form. Of these, $\mathrm{Bcl}-\mathrm{x}_{\mathrm{L}}$ has antiapoptotic properties similar to $\mathrm{Bcl}-2$.

VEGF (vascular endothelial growth factor): VEGF is a cytokine that mediates numerous functions of endothelial cells, including proliferation, migration, invasion, survival, and permeability. VEGF is also known as vascular permeability factor. VEGF naturally occurs as a glycoprotein and is critical for angiogenesis. Many tumors overexpress VEGF, which correlates to poor prognosis. VEGF-A, -B, -C, -D, and -E are members of the larger family of VEGF-related proteins.

Angiogenesis: The process involved in the generation of new blood vessels. While this is a normal process that naturally occurs and is controlled by "on" and "off" switches, blocking tumor angiogenesis (antiangiogenesis) disrupts the blood supply to tumors, thereby preventing tumor growth.
$\mathrm{BH} 3$-binding domain: Hydrophobic groove present in Bcl-2, and some related proteins, that acts as a binding target for the $\mathrm{BH} 3$ domain of other proteins. The $\mathrm{BH} 3$-binding domain is the primary target for certain small molecule inhibitor drugs that prevent $\mathrm{BH} 3$-domain binding and induce apoptosis.

TW-37 (TW37): Small molecule inhibitor of Bcl-2 and Bcl-2 family of anti-apoptotic proteins, induces apoptosis in sensitive cells. TW-37 is an example of a new group of molecules designed to inhibit Bcl-2 and related proteins by targeting their BH3-binding domain. TW-37 is currently in pre-clinical trials.

(-)-Gossypol: Negative enantiomer of a polyphenolic molecule derived from the cotton plant. Having male contraceptive properties, it is a natural compound known to inhibit $\mathrm{Bcl}-2$ and $\mathrm{Bcl}-\mathrm{x}_{\mathrm{L}}$ function via targeting their BH3-binding domain. (-)-Gossypol is currently entering clinical trial for cancer treatment.

Oblimersen (Genasense): Antisense oligonucleotide inhibiting Bcl-2 mRNA translation and therefore protein production. This is an example of a genetic inhibitor of $\mathrm{Bcl}-2$ currently in clinical trial. 